\title{
Pogonophora from the Eastern Tropical Pacific, including Two New Species of Siboglinum
}

\author{
EDW ARD B. CUTLER ${ }^{1}$
}

\begin{abstract}
Two species of Pogonophora are described from the tropical Pacific from a depth of $1354 \mathrm{~m}$. They belong to the genus Siboglinum and both are new species, $S$. albatrossianum and $S$. ecuadoricum. Empty tubes of another pogonophore are also described. This material represents the earliest known collection of pogonophores.
\end{abstract}

THE POGONOPHORAN MATERIAL described below is historically interesting as it was collected in 1888 by the U. S. Fish Commission steamer "Albatross." This was 11 years before the "Siboga" Expedition, whose collections contained the first specimens of this group to be described (Caullery, 1914; Southward, 1961). The "Albatross" material went unnoticed in the U. S. National Museum until 1959, when Dr. F. M. Bayer of the University of Miami discovered it among some pennatulids.

Dr. Fenner A. Chace was good enough to let me borrow it and with the help of Dr. Eve Southward I have been able to describe these new species. I am also indebted to Mr. Grant S. Lashbrook for the illustrations and to Dr. Paul J. Osborne for the use of his microscope.

As this material has been preserved in alcohol for 76 years, it is rather brittle and difficult to work with. Some distortion due to shrinkage is possible but it seems advisable to describe the specimens in spite of this. Other than Lamellisabella ivanovi (Kirkegaard, 1961) these are the only pogonophores to be described from this region of the Pacific Ocean. All the material came from "Albatross" Station 2793, and has been deposited at the U. S. National Museum in Washington, D. C.

\section{Collection Data}

LOCALITY: Off Cape San Francisco, Ecuador POSITION: $01^{\circ} 03^{\prime} \mathrm{N}, 80^{\circ} 15^{\prime} \mathrm{W}$

\footnotetext{
${ }^{1}$ Formerly at Lynchburg College, Lynchburg, Virginia. Present address: Department of Zoology, University of Rhode Island, Kingston, R. I. Manuscript received April 14, 1964.
}

DEPTH: 741 fathoms $(1354 \mathrm{~m})$

ВОTTOM DATA: green mud, $3.5^{\circ} \mathrm{C}$

DATE OF COLLECTION: 3 iii. 1888

Siboglinum albatrossianum sp. nov.

Figs. 1-6, $13 A-E$

HOLOTYPE: USNM 31824; PARATYPE: USNM 31825

DESCRIPTION: This species is represented by 47 tubes, 24 containing parts of animals. As the significance of the material was not realized at the time of collection it was probably handled rather carelessly. Consequently, I was unable to find any one animal which was not damaged.

The tubes have the characteristic ringed appearance on the major portion. The anterior and posterior ends are thin, colorless, and wrinkled (possibly from dehydration). This wrinkled appearance is present in the colorless interspaces between the rings on many of the tubes. These interspaces are often pinched or indented and have even imposed a pseudometamerism on the body. The shade of brown in the rings becomes darker and the rings also become longer toward the middle of the tube. The diameter of the tube is $0.11-0.125 \mathrm{~mm}$ while the length of the rings is $0.014-0.026$ $\mathrm{mm}$, always less than one-fourth the diameter. The rings are paired throughout with frequent connections between the pairs in the middle region. The longest tube in the collection is $90 \mathrm{~mm}$.

One specimen measures $7.9 \mathrm{~mm}$ from the anterior end to the first girdle. The width of the trunk varies from 0.09 to $0.12 \mathrm{~mm}$. The forepart (promesosome) is $1.35-1.46 \mathrm{~mm}$ long. 


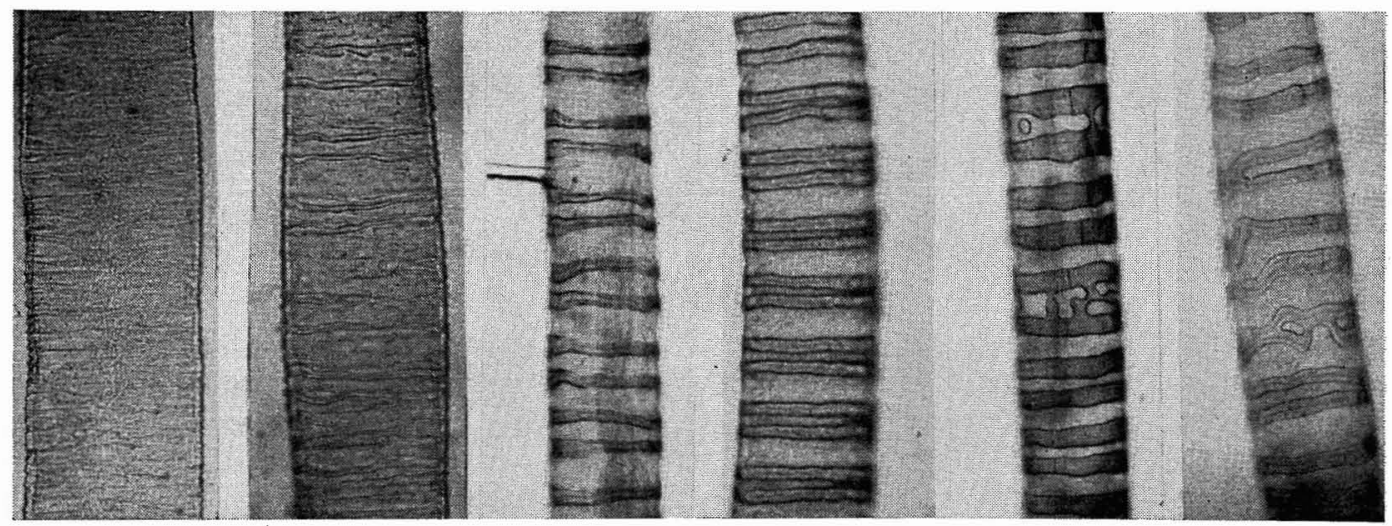

FIGs. 1-6. Different regions of the tube of $S$. albatrossianum from anterior to posterior. 1, Clear, limp region. 2, Thin, pale rings appearing. 3 and 4, Lengtaening rings in midportion. 5 and 6, Approaching the posterior end, where the rings become more irregular.

The width of the mesosome is $0.09-0.12 \mathrm{~mm}$; the ratio of width to length being $1 / 12-1 / 14$. The cephalic lobe is small, rounded, appears quite glandular, and lacks a pretentacular groove. Just behind the base of the tentacle there is a groove on the ventral side only. The tentacle measures $35-45 \mu$ in diameter and bears two rows of pinnules. The length of the pinnules varies but usually exceeds the diameter of the tentacle.

In unstained material the bridles are very difficult to distinguish. After staining with hematoxylin they can be seen as very thin lines which join ventrally but leave a small gap on the dorsal side. There are short, delicate, transverse lines crossing the bridles, as in $S$. tenue (Ivanov, 1963:240). There are no visible glands behind the bridle. The bridle is in the middle of the promesosome.

The metameric glands of the metasome are present but very poorly defined. There are two girdles which are from 0.55 to $0.63 \mathrm{~mm}$ apart and each consists of one row of platelets (uncini). The platelets are 11-15 $\mu$ long with two characteristic groupings of small teeth. In the posterior region there are a few scattered papillae. The spermatophores are more or less spindle-shaped and measure about $70 \mu$ by $7 \mu$. I was unable to distinguish their filament.

This species is similar to $S$. weberi, but different in the following aspects: forepart proportionally a little longer, bridle about half way along the forepart, two rows of pinnules, much larger spermatophores, girdles closer together, and more double tube rings. It differs from $S$, veleronis in that the bridle is tarther back on the mesosome, the glandular papillae are less well developed, it lacks the cylindrical pores on the sides of the mesosome, and the toothed platelets are of a different type.

Siboglinum ecuadoricum sp. nov.

Figs. 7, 8, 13F

HOLOTYPE: USNM 31822; PARATYPE: USNM 31823

DESCRIPTION: This species is represented by two unsegmented tubes, each containing an ani-

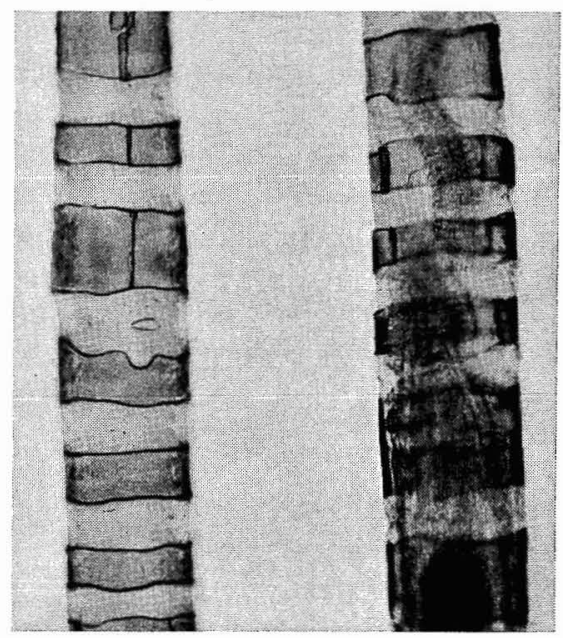

FIGS. 7-8. Tube of $S$. ecuadoricum. 7, Middle region. 8, Portion of the tube containing the anterior part of the animal and part of the tentacle. 
mal. The longest tube measures $40 \mathrm{~mm}$ and the diameter varies from 0.11 to $0.13 \mathrm{~mm}$. One striking feature of this species is the length of the solid, yellowish rings and the interspaces. Most rings measure about $0.05 \mathrm{~mm}$ but vary from 0.04 to $0.09 \mathrm{~mm}$ long, while the clear spaces are usually about $0.045 \mathrm{~mm}$. The edges of the rings are irregular. The anterior and posterior regions of the tube are clear and there is a short transition area from the ringed to the clear region, rather than a gradual fading out as in the preceding species. There are several species of Siboglinum with rings of a comparable length, but either the diameter is larger (e.g., S. japonicum and $S$. timorense) or else they have paired rings or doublets or are more regular in appearance (e.g., S. pusillum and S. hyperboreum).

The post-annular region is largely missing in both specimens but other measurements are as follows (in $\mathrm{mm}$ ):

\begin{tabular}{l|l|c}
\hline \multicolumn{1}{c|}{ MEASUREMENT } & A & B \\
\hline Anterior girdle to tip & & \\
$\quad$ of cephalic lobe & 6.9 & 10.8 \\
Distance between girdles & 0.91 & 1.8 \\
Diameter of trunk at girdle & 0.116 & 0.105 \\
Forepart of body: length & 0.77 & 0.69 \\
Forepart of body: width & 0.105 & 0.093 \\
Ratio of width to length of & $1 / 7$ & $1 / 7$ \\
$\quad$ forepart & \\
\hline
\end{tabular}
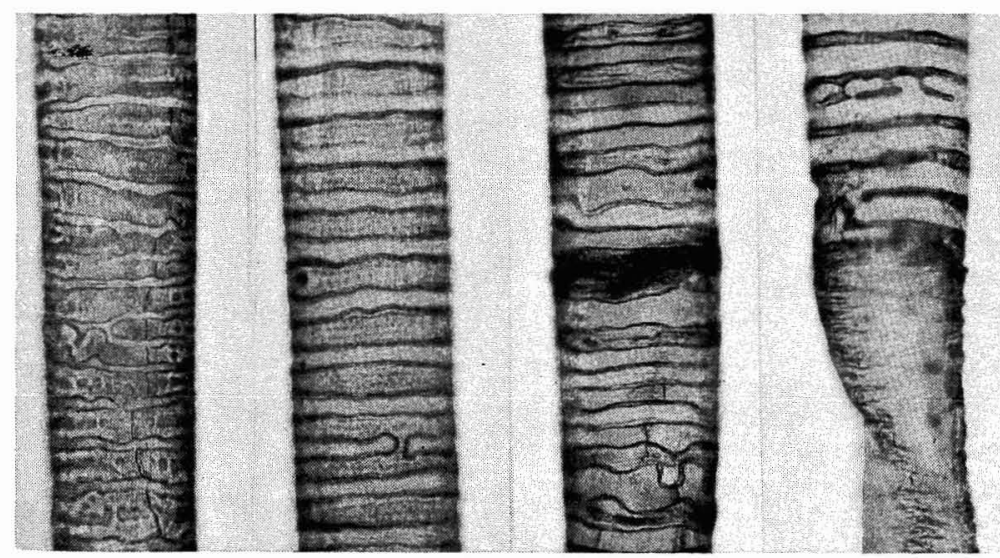

Figs. 9-12. Tube of ? gen. et sp. 9, The abrupt transition from the clear region to that of narrow rings. 10, Anterior section showing dark area where two segments come together. 11, Regular rings in the midportion. 12, Posterior region showing the double nature of the rings with irregular openings between the members of the doublets.
The cephalic lobe is small, rounded, and somewhat flattened. The tentacle is $35-45 \mu$ in diameter and there are two rows of pinnules present. The length of the pinnules is about equal to the diameter of the tentacle. A posttentacular groove is present and, in addition, there are two partial grooves, or wrinkles, farther back on the mesosome.

The bridles are colorless and not very distinct. They join ventrally but there is a gap on the dorsal side about $1 / 4$ the diameter of the mesosome. There are no other distinguishable features on the pro-mesosome.

The mesosome-metasome division is cleat and there are about 30-35 pairs of metameric papillae present, followed by scattered glandular patches. There are two girdles which do not completely encircle the trunk. They are composed of a single row of platelets which are about 13-14 $\mu$ long. The spermatophores are long, thin (about $80 \mu$ by $7 \mu$ ), and pointed at both ends. The filament was not observed.

\section{Figs. 9-12}

A third species is represented by three empty tubes, 15, 18, and $79 \mathrm{~mm}$ long. The longest tube is divided into three regions: $2 \mathrm{~mm}$ clear and limp, $16 \mathrm{~mm}$ of obvious segmentation 


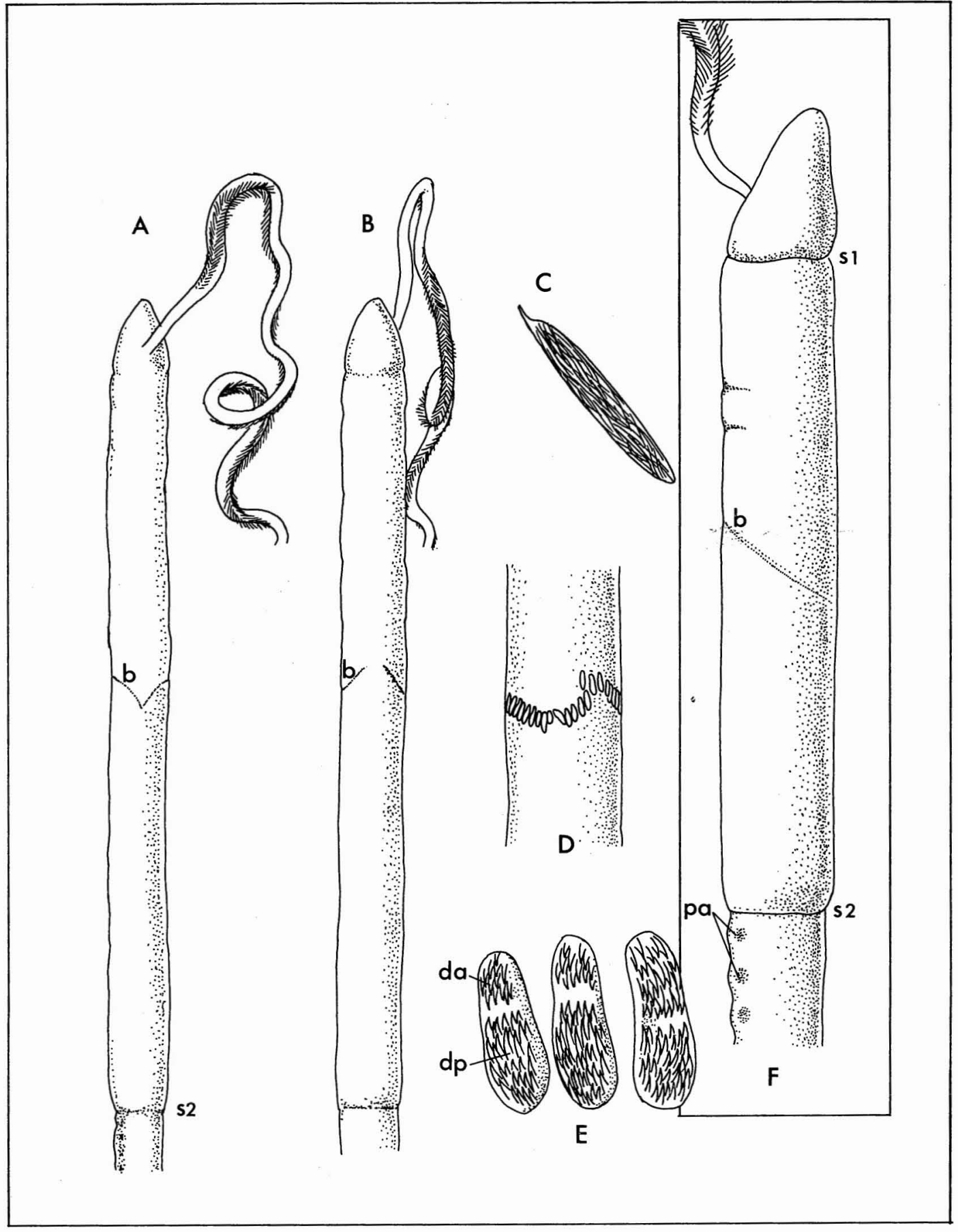

FIG. 13. $A-E$, Siboglinum albatrossianum. $A$, Forepart of body from ventral side; $B$, from dorsal side; $C$, spermatophore; $D$, region of a girdle; $E$. toothed platelets.

$F$, Siboglinum ecuadoricum, side view. $b$, Bridle; da, anterior teeth; $d p$, posterior teeth; pa, papilla; $s_{1}$, post-tentacular groove (between protosome and mesosome); $s_{2}$, groove between mesosome and metasome. 
with rings (mostly unpaired), and a $60 \mathrm{~mm}$ ringed portion where the segmentation is not apparent. This breaking down of the segmentation is similar to that of $S$. sumatrense, but the rings are more like those of $S$. silone. The other two pieces are segmented, one being rather dark chestnut brown and more rigid.

The diameter of the two lighter tubes is $0.16-0.17 \mathrm{~mm}$ and the darker, sturdier one measures $0.18-0.19 \mathrm{~mm}$ across. The rings are very thin toward the ends of the tube (about $9 \mu$ ), gradually becoming about 18-19 $\mu$, and then, where the rings double, they measure about 36-40 $\mu$ long, or about $1 / 4$ the diameter of the tube. There are from 16-24 rings per segment.

\section{REFERENCES}

CAUllery, M. 1914. Sur les Siboglinidae, type nouveau d'Invertebres recueilli par l'expedition du Siboga. C. R. Acad. Sci., Paris 158: 2014-2017; Bull. Soc. Zool. Fr. 39:350-353. Ivanov, A. V. 1963. Pogonophora. Consultants Bureau, New York; Academic Press, London. xvi +479 pp.

KirkegaARD, J. B. 1961. Pogonophora, III. The genus Lamellisabella. Galathea Rep. 4:7-10. SoUTHWARD, E. C. 1961. Pogonophora. Siboga Exped., Monogr. 25 (3). 22 pp. 